\title{
A survey of graduates in library and information studies at Comenius University Bratislava (Slovakia)
}

\author{
Miriam Ondrišová, Lucia Lichnerová \\ Comenius University Bratislava
}

\section{Introduction}

The Department of Library and Information Science at the Faculty of Arts (Comenius University in Bratislava, Slovakia) is the oldest and the most prestigious university workplace in the field of Library and Information Science in Slovakia. In addition to the pedagogical process, the Department is also an important research unit in the field. At present, the Department provides an accredited Bachelor's, Master's and PhD. degree studies. At the bachelor level we also offer a combined study with German, History and Museology. We prepare the future generations of information specialists for managing information flow, information explosion, for the support of knowledge economy. We educate the experts to protect the cultural heritage of historical libraries, manuscripts and old prints and also experts in information architecture, information ecology and reader's interests. During the more than 50 years the department has had about 1200 graduates.

As the department has long and rich history, it has undergone many changes concerning:

- The name of the department itself. Our Department was founded in 1961 as the Department of Librarianship, later (1967) it was renamed to the Department of Library Science and Scientific Information, in 1991 to the Department of Librarianship and Information Science and 1999/2000 to the Department of Library and Information Science (Lichnerová and Špániová, 2011).

- The forms of the study and its length,

- The transformation of study curricula (also combined with English, French, German, Latin, Hungarian, Polish, Serbo-Croatian, Pedagogy, Andragogy, Philosophy, Sociology),

- The specialization focus (e.g. literary specialization, specialization in library information systems, library management, historical book collections...) 
The changes reflected the theoretical and practical progress in the field and the needs of the graduates for better employment as well. The history of the department has shown the significant role of the feedback of our graduates on the forming of the content of the study program. The Department of Library and Information Science tries to maintain the contact with its graduates via the Facebook page, various websites associating the professional community as well as through the newly established Club of the Department Friends. In addition, we perform the comprehensive graduate survey to obtain valuable information about the provided study program and suggestions to improve form and content of education for future information professionals. We performed the graduate surveys in 1976, 1990 and 2001. The last survey in 2001 showed following results:

- $40 \%$ of graduates worked in the libraries,

- $59 \%$ of graduates worked in the commercial sector,

- $68 \%$ of respondents were very satisfied with the study,

- only 2 respondents were unemployed,

- The LIS was evaluated as useful and various,

- Because of financial reasons our graduates preferred the commercial sector to the libraries (Krištofičová and Matthaeidesova, 2001).

\section{Basic information about the survey}

In September 2017 we conducted a new survey of our graduates to find out information about their professional experience and study evaluation. The survey was implemented within the scope of the project VEGA1/0066/15 Modelling of the information environment of digital scholarship. It included all graduates who completed the Library and Information Studies (LIS) in the period 20072017. The questionnaire was distributed to 231 graduates. The response rate was on the level of 39\% (91 graduates filled in the questionnaire). Regarding the methods, the survey was conducted via a questionnaire, which contained 21 open, semi-closed and closed questions. Some types of questions were also scaled. Methods of the evaluation used in results analysis were mainly mathematical statistics, synthesis and frequency analysis. The questionnaire was distributed via e-mail, Facebook, department website, and other librarian Facebook websites. The survey's primary objective was to obtain information about the experience of graduates entering the labor market, focusing on employment, occupations and the relationship between jobs and education. Other objectives were: 
- To find out the success of graduates in the job searching during and after the study,

- To quantify the number of graduates working in the field of Library and Information Science,

- To identify the theoretical knowledge and practical skills, most commonly used in their current work,

- To get evaluation of the graduates of the LIS.

\section{Work experience}

2.1 Work experience during the studies

The questionnaire showed that most of our graduates had already worked during their studies (Graph 1). Up to 78\% had a regular part-time job, 69\% mentioned that the work experience during the studies helped them to find their current job (Graph 2). Two fifths of respondents (41\%) looked for the job in the area of LIS, but only $26 \%$ were successful (Graph 3 ). From the above-mentioned information, it is clear, that the interest in the job in the field of LIS was higher than the real possibilities. At this point it must be also said, that maybe the possibilities were sufficient, but only not accepted by graduates due to time or financial reasons.

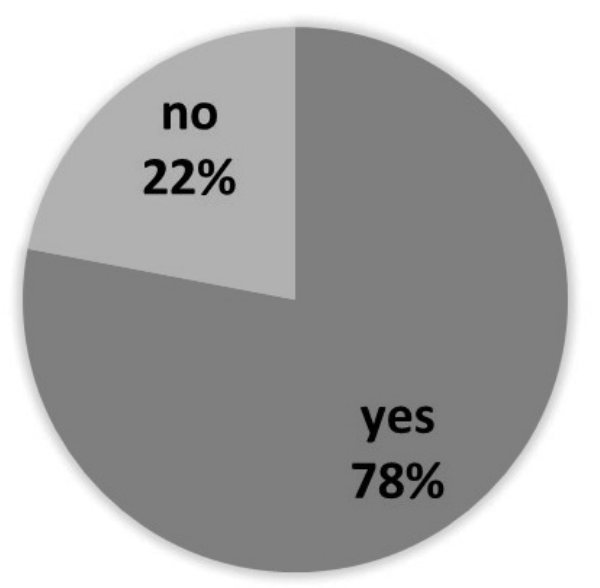

Graph 1 Working during the study 


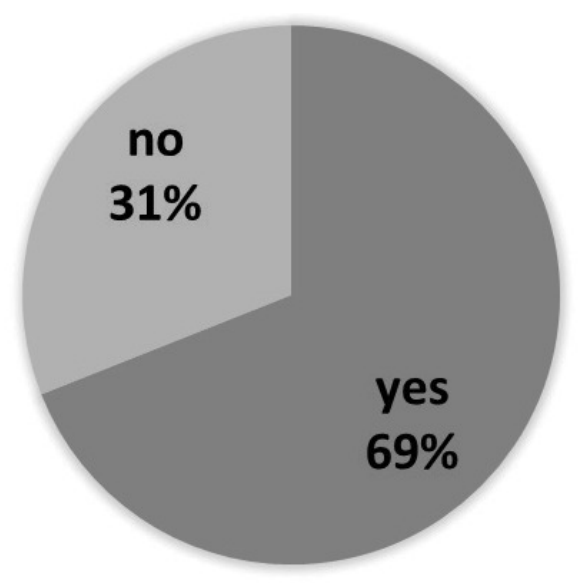

Graph 2 The importance of work experience during the study for finding a current job

Almost every fifth respondent (17\%) worked in the library, on the position of the librarian or cataloger. They worked in different types of libraries (in academic, scholarly, public, commercial or special libraries). Up to $9 \%$ of respondents used their professional skills outside the library - in the commercial sector. These graduates used their knowledge particularly in the field of information systems, digitalization and retrieval systems on the positions as information system consultant, programmer, bookseller, digitization assistant,... As graph 4 presents others ( $74 \%$ ) worked on different positions outside the field of LIS, most of them as assistants, sales persons, programmers, but also as rescue swimmers, cleaners, au pairs, technicians or accountants.

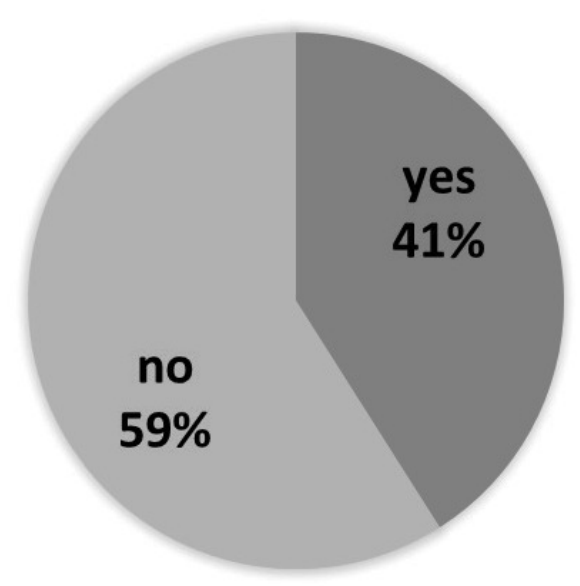

Graph 3 Job searching in the field of LIS during the study 


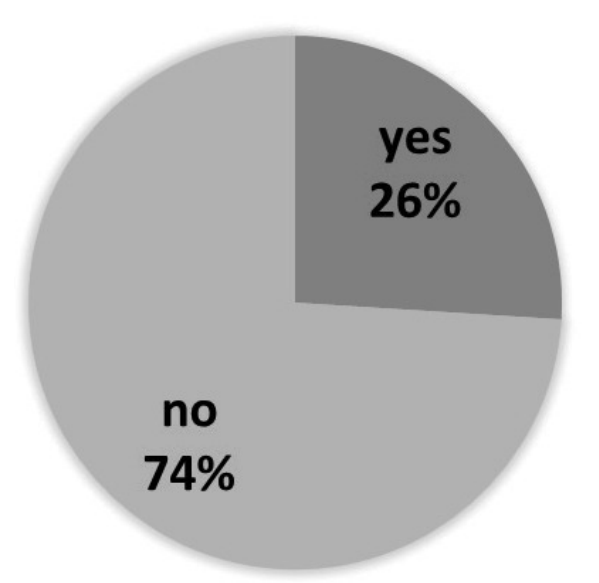

Graph 4 Job in the filed LIS during the study

2.2 Work experience after graduation

Employment after graduation is one of the most important criteria in the process of choosing the field of study for future students. According to the results, our graduates had no problem to employ. They found their job very quickly after graduation.

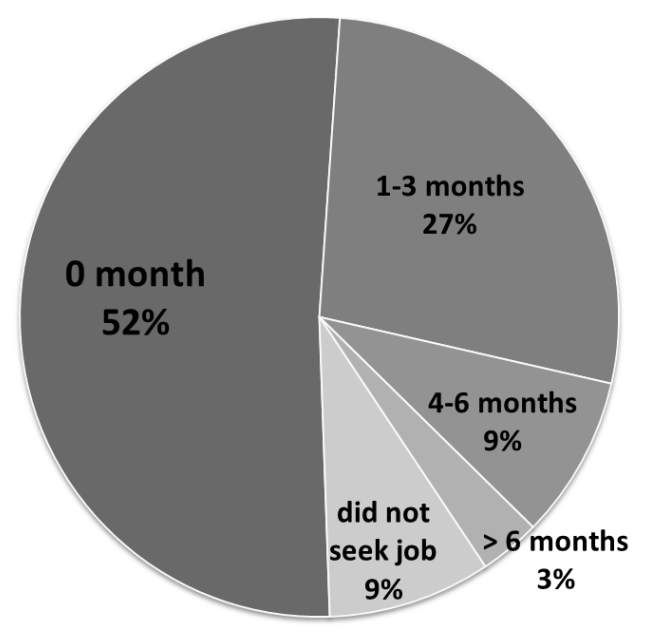

Graph 5 Period of job finding after graduation 
A graph 5 shows more than half of graduates could find their job immediately after graduation (even before graduation). Almost one third of graduates could find their job within 3 months after graduation 9\% could find their job within 4 and 6 months after graduation, 9\% of graduates didn't seek their job at all.

The graduates were employed in many different areas. That's why we divided the employers into several categories: first of all we defined libraries as a special category because of the context of our field. Other employers were divided into commercial sector including companies with various areas of interest; organizations owned by state; government organizations such as ministries, and lastly non-profit organizations.

More than a half of the graduates (56\%) found their first job in commercial sector, one quarter in libraries and $14 \%$ in organizations owned by state (Graph $6)$.

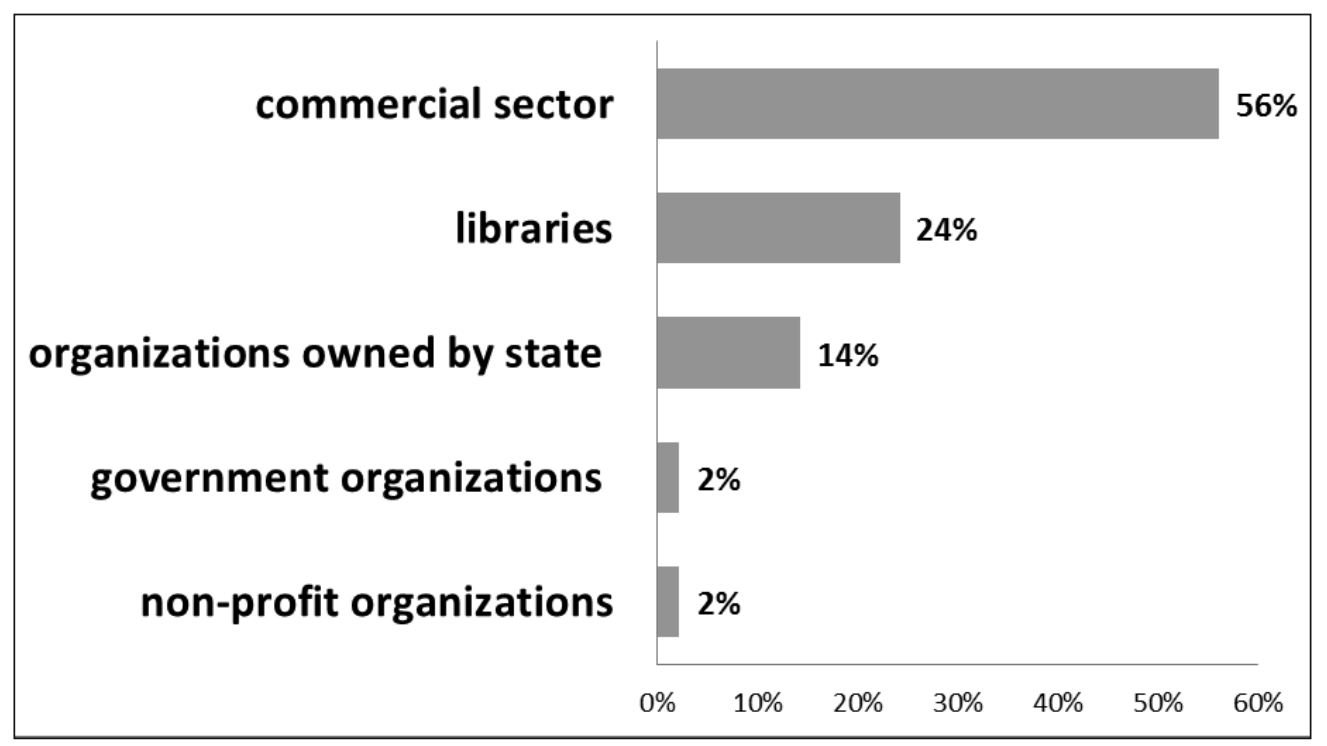

Graph 6 First employers of respondents after graduation

Every second respondent found his/her job in the field of library and information science right after their graduation. Wide scope of study enables graduates to work not only in libraries but also in the various types of organizations and positions:

- 22 graduates worked in libraries on a position as librarians responsible for acquisition, catalogization, reprographic service, evaluation and registration of scholar publications 
- 17 in commercial sector on positions focused on development and testing the websites, information architecture, usability, accessibility, SEO, user experience, design and testing the library information systems, design and manage database systems

- 1 in non-profit organization as information specialist

- 7 in state-owned organizations on positions as information specialists, archivists, and catalogers

- 2 graduates worked in government organizations.

The behavior of our graduates during their working career was the next objective we were interested in. When we compared the first and the current employers, we found out that a part of respondents changed their job (Graph 7). The percentage of graduates working in libraries increased from 24 to $29 \%$. The percentage of graduates working in commercial sector decreased from 56 to $49 \%$.

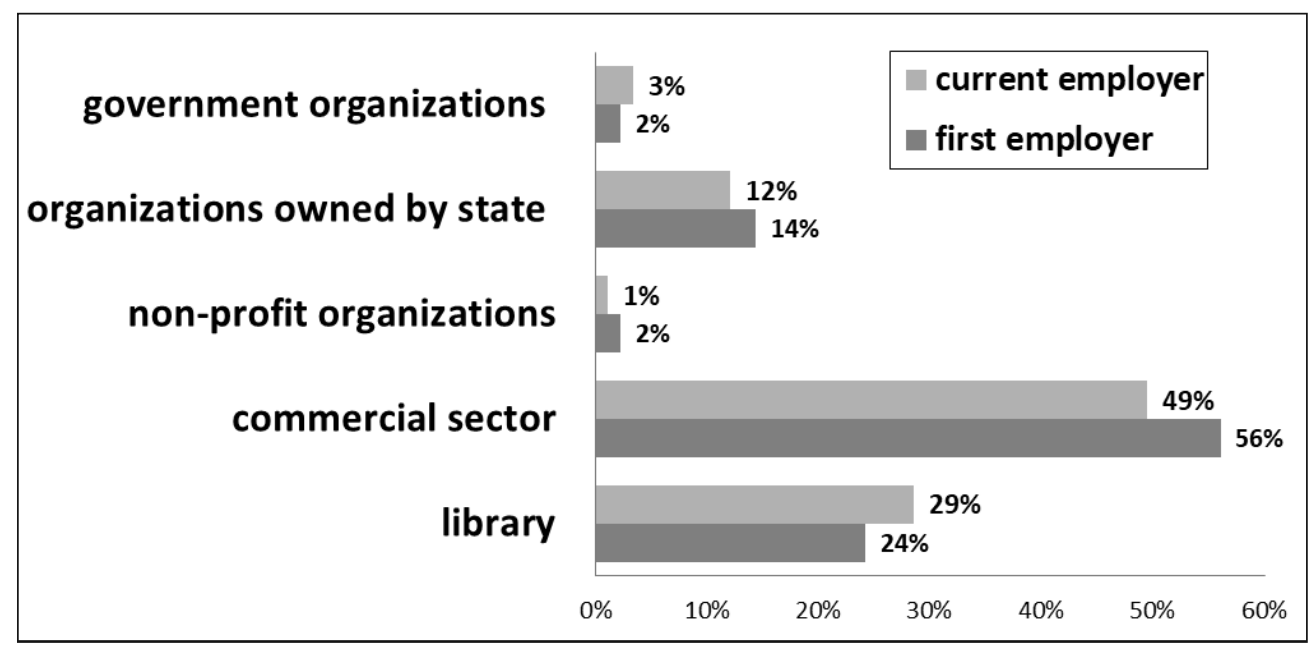

Graph 7 First and current employers of graduates

Currently, percentage of graduates working in field of LIS has stayed the same. More than half of graduates (54\%) still work in the field. But the structure of employers slightly changed:

- 26 of respondents work in libraries

- 14 in commercial sector, on positions as UX designer, web developer, information specialist, library information system tester and designer, database specialist 
- 7 in state-owned organizations on positions of information specialist, archivist, curator of digital objects, teacher

- 1 in non-profit organization

Graduates who do not work in the field of LIS are on positions as project manager, change manager, account manager, office manager, HR manager, tester, and editor.

\subsection{Reasons for choosing the current job}

Multiple-choice questions in the survey brought information about preferences of our graduates. The working time was the most frequently mentioned reason for choosing the current job. It was an important criterion for more than a half of the graduates (55\%). About $40 \%$ of graduates mentioned financial conditions, the majority of them work in commercial sector, none in the library. Therefore it is not surprising that these graduates didn't mention the work in the field as the reason for choosing that job. The work in the field of LIS was marked by $40 \%$ of respondents; all of them have a job in the field. One third of our graduates prefer career growth as a reason for choosing job.

\section{Evaluation of the study}

3.1 Knowledge, skills, and experience of LIS in the current job

The questionnaire brought also information about the knowledge, skills and experience of LIS used in the current job (Graph 8). All respondents expressed their opinion to this question. Each of them used at least a part of the professional knowledge in today's profession; three respondents said they used almost all the knowledge. The mostly used hard skills in current job are following:

- creating, evaluation and optimization of websites,

- cataloguing,

- information retrieval,

- design and management of databases and information systems, library management and others (see graph 8 ). 


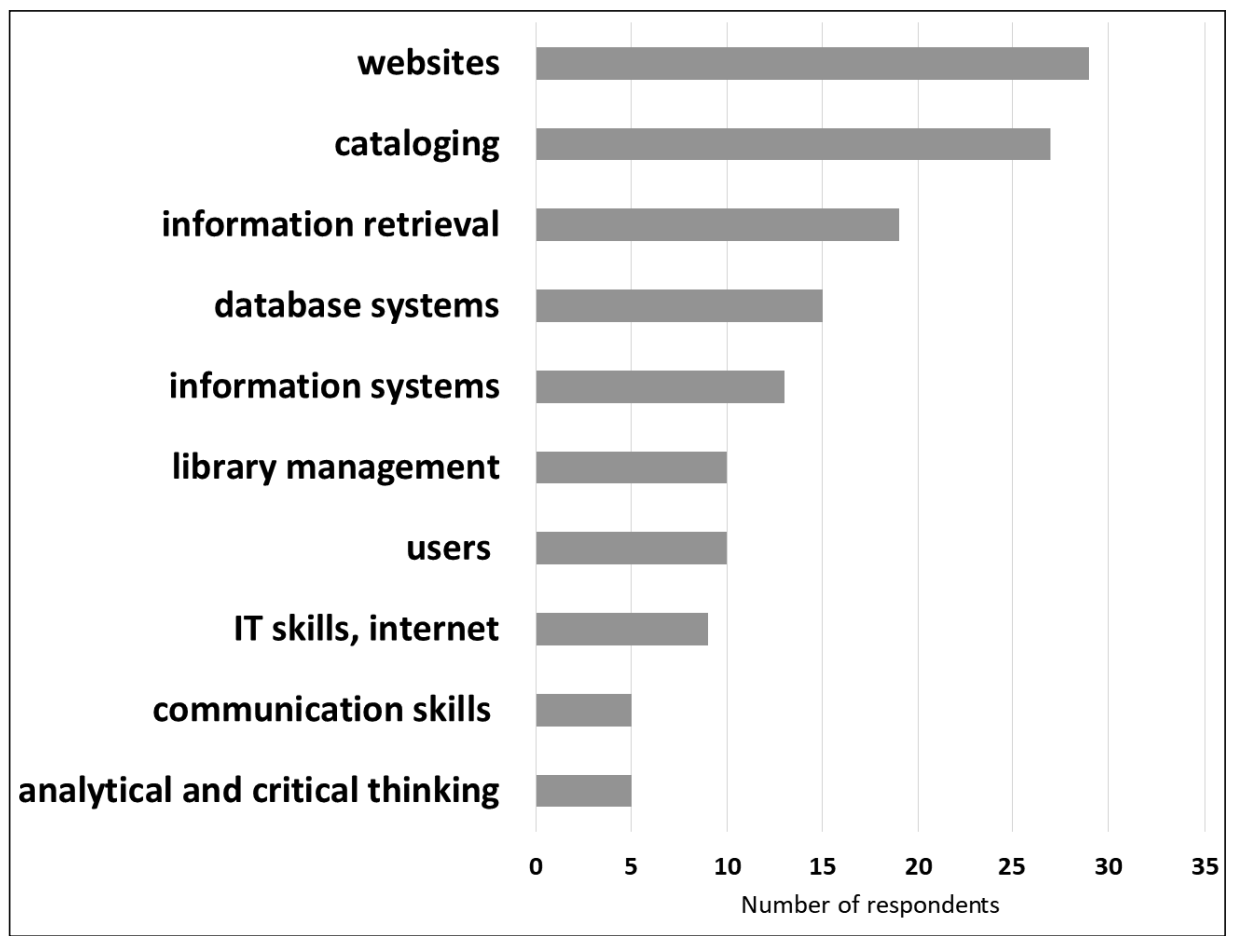

Graph 8 Knowledge, skills and experience of LIS used in the current job

Regarding soft skills, the respondents mentioned mainly analytical and critical thinking as well as communication skills. It is also interesting to find out, in which professions the hard skills are mostly used.

The skills from the field of websites are used in jobs such as software tester, head of the secretariat, project manager, team designer, librarian, development specialist, UX designer, web developer or bank coordinator.

Knowledge from the field of cataloging is used in the work process, mainly by employees in library; information retrieval is widely used by respondents who primarily work as cataloging librarians or librarians, less data editors, helpdesk analysts, HR managers, and junior managers.

Database expertise is important for software developer, editors, archivists, operational administrators, technicians, managers, librarians, sales-persons, business specialists, and bank coordinators.

The graduates who use the cataloging in their profession use also knowledge in a field of information systems. Those working in the commercial sector use also database systems. 


\subsection{Evalutaion of the LIS regarding the employability}

The next results relate to the evaluation of the LIS regarding the employability. This question was scaled and contained the answers in a scale from 1 to 5 (absolutely yes / absolutely no). How we can see on the graph 9, the majority of our graduates evaluated their study as useful regarding the employability. Only $19.7 \%$ are not satisfied with the LIS in the context of employability.

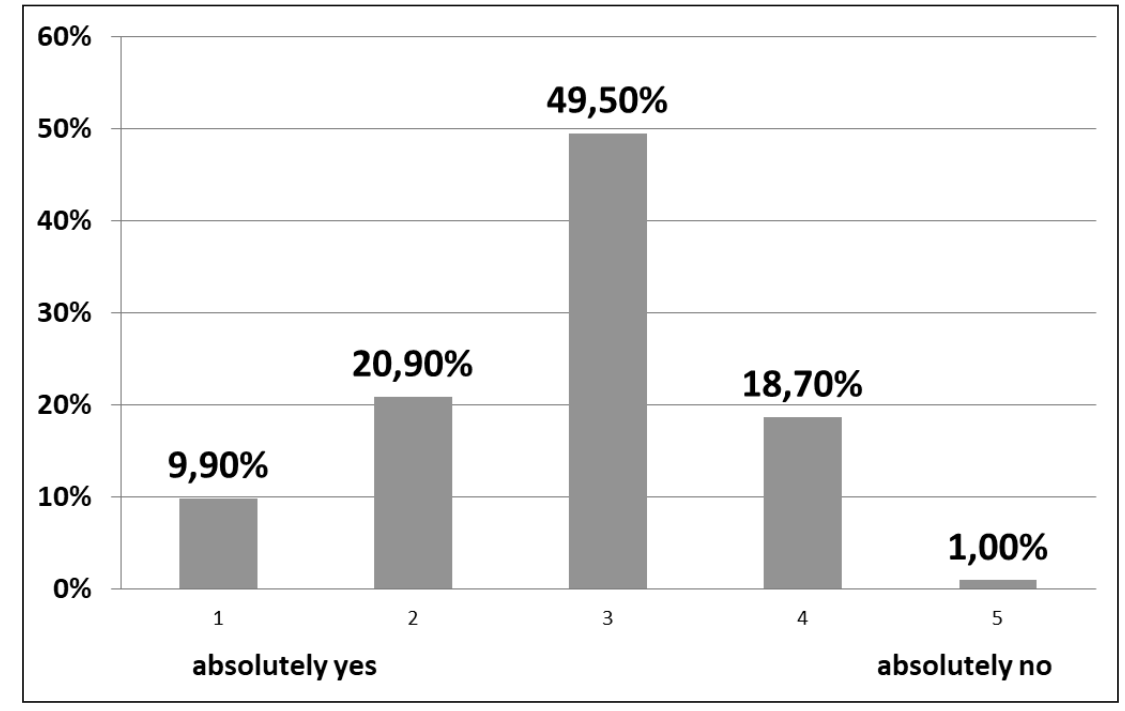

Graph 9 Evaluation of the effectiveness of LIS regarding the employability

\subsection{Competitive advantage of graduates of LIS}

The feedback from respondents about their competitive advantage in comparison with the graduates of other disciplines was also interesting. The top competitive advantage mentioned in the survey was the versatility. As the graduates argue, wide scope of study provides them opportunities to employ not only in libraries but also in many other areas. Knowledge in the field of information technology, information system, database system and web design enables them to effectively communicate with programmers, designers and product managers. The next mentioned competitive advantage is knowledge of information retrieval and analysis. The acquired experiences in information retrieval, evaluation of information sources and information verification as well as experiences with using of external licenced databases are powerful parts of their professional everyday life. Quite interesting is that the graduates perceive as a competi- 
tive advantage the fact, that the LIS is an uncommon discipline. It gives them a unique position on the labor market, as one of the respondents mentioned: "Many employers know nothing about library and information science and so it is often a good start of job interview." Last but not least the graduates consider as a competitive advantage their soft skills and individual competences, practice and foreign languages.

\subsection{Feedback on LIS}

Almost $26 \%$ of respondents had no suggestions for improvement on the LIS. Three quarters expressed their opinion to several topics. As graph 10 presents the majority criticized the lack of practice - this comment was mentioned by those graduates, who ended their LIS before our new study plans were implemented. Up to 18 respondents missed programming in the study. This was due to the fact, that they work with information technology and programming skills would help them to solve real problems which occur in their working live. Further comments were only marginal: graduates would like to learn e.g. more about project management, excel, publishing evidence, historic book collections, marketing, social networks, internet or new media.

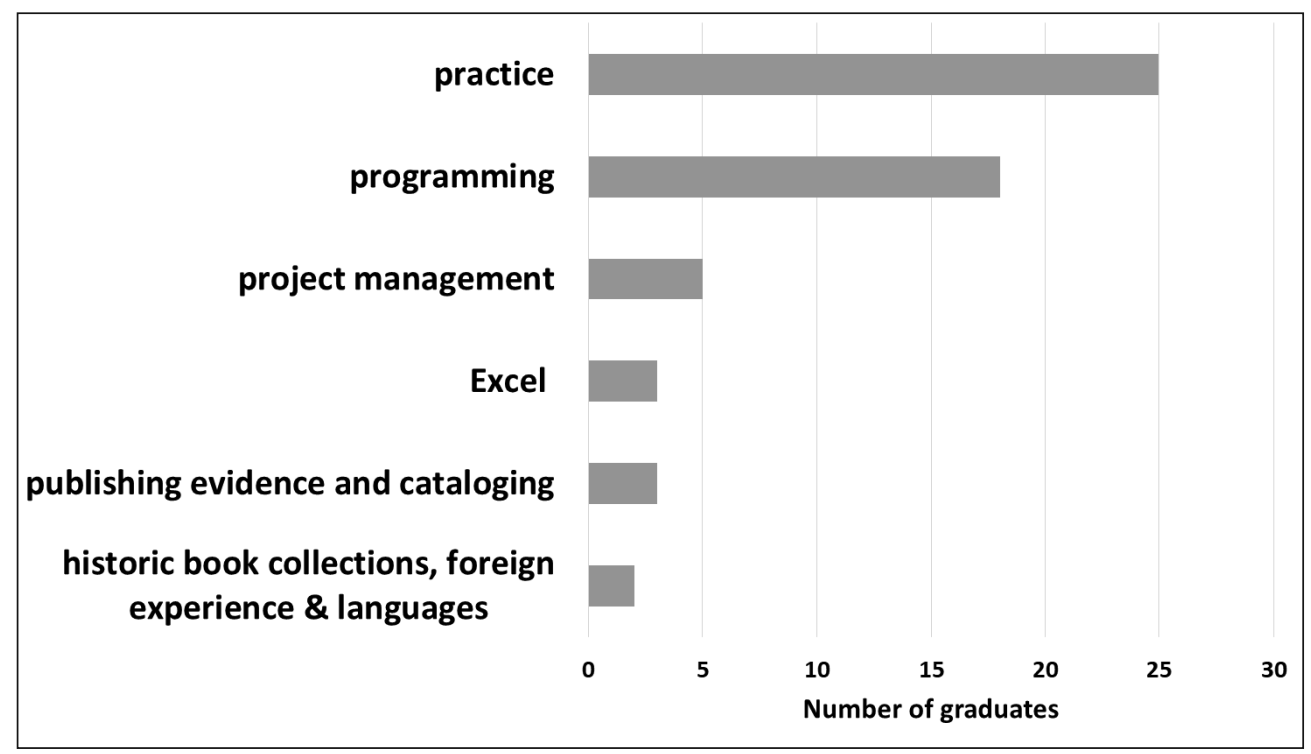

Graph 10 Missed topics in LIS 


\section{CONCLUSION}

For the further development and modernization of LIS, the survey brought interesting, useful and also some surprising results for us. The work during the study is perceived by the graduates as a good experience and start point for their future employment. The respondents mentioned enough opportunities to work during the study and $41 \%$ of them searched for a job in the field of LIS.

Regarding the work experience, the most important result of the survey is that our graduates have no problem to find a job after the study. More than three quarters of them found their job in 3-month period after graduation. Every second respondent works in the field of LIS, half of them in libraries and half of them mostly in commercial sector on position of UX designer, web developer and information specialist, library information system tester, designer or database specialist.

LIS is perceived and evaluated by graduates positively. It offers competitive advantages in terms of versatility, specific (uncommon) but unique discipline and the wide range of possibilities for employment. All respondents use the knowledge, skills and experience from the study in their current job. The most used knowledge and skills are web design, cataloging, information evaluation, organization and database management.

One of the main motives for implementing of our survey was innovation of the education content according to requirements and needs of the current practice. Some suggestions of graduates, e.g. project management, data analysis and visualization, design of web pages, have been already included to study plans in form of new courses or changed content. The most often mentioned suggestions concerned incorporating more practice and project learning to the study. Lot of respondents need deeper knowledge and skills in the field of information technology and programming in their work.

Library and information science is a dynamic field of science and so the preparation of information professionals during the study must be continuously innovated to stay in touch with the latest theoretical and practical progress. The reflection of graduates is a valuable source of inspiration and navigation for the next improvement of study plans. 


\title{
References
}

Krištofičová, E. and Matthaeidesova, M. (2001): Uplatnenie absolventov Katedry knižničnej a informačnej vedy FF UK v praxi. Knižnica, 2. 8. 434-437. http://www.snk.sk/sk/domov/14-o-kniznici/804-archiv-kniznica-2001.html

Lichnerová, L. and Špániová., M. (2011): Katedra knižničnej a informačnej vedy FiFUK jubiluje: krátky pohl'ad na 60 rokov vysokoškolského štúdia knihovníctva. Ikaros 15. 12. 1-4 http://www.ikaros.cz/katedra-kniznicnej-a-informacnej-vedy-fifuk-jubiluje-kratky-pohlad-na-60-rokov-vysokos kolskeho-studi

\begin{abstract}
The Department of Library and Information Science at the Faculty of Arts (Comenius University in Bratislava, Slovakia) is the oldest and the most prestigious university workplace in the field of Library and Information Science in Slovakia. A 2017 a survey of the Department's graduates shows that their present jobs require creating, evaluation and optimization of websites, cataloguing, information retrieval, design and management of databases and information systems. Besides of these hard skills, they are required to have soft skills, such as analytical and critical thinking as well as communication skills.
\end{abstract}

